\title{
A Rare Case Report of the Posterior and Bilateral Persistent Hyperplastic Primary Vitreous (PHPV)
}

\author{
Japhet Pobanou Thera*, Tiama JM, Konipo A and Dakouo P \\ Institute of African Tropical Ophthalmology, Bamako, Mali \\ *Corresponding Author: Japhet Pobanou Thera, Institute of African Tropical \\ Ophthalmology, Bamako, Mali.
}

Received: May 14, 2020

Published: June 26, 2020

(C) All rights are reserved by Japhet Pobanou

Thera., et al.

\begin{abstract}
Purpose: The aim of our study was to report a rare case of persistent hyperplastic primary vitreous.

Case Report: A 4-year-old girl was brought by her parents for impaired visual acuity. The examination of the lens found a tiny opacification. Fundoscopy revealed a membranous proliferation extending from the papilla to the posterior surface of the lens.

Discussion: The persistent primary vitreous is a congenital abnormality. It is due to a failure of regression of the embryonic vitreous to which is added the persistence of the hyoid artery. It occurs around the 6th week of embryo development.

Conclusion: Persistent hyperplastic primary vitreous (PHPV) is a rare congenital anomaly. It has many forms. The Posterior form and the isolated bilateral one is rare.

Keywords: Persistent Primary Vitreous; Posterior; Bilateral
\end{abstract}

\section{Introduction}

The persistent primary vitreous is a congenital anomaly caused by non-regression of fetal hyaloid vascularization [1]. It is a rare ocular malformation of unknown origin, classically unilateral and occurring during embryogenesis [2]. It is classified in three forms: anterior, posterior and mixed. Mixed forms are the most common and reach a frequency of $77 \%$ in some series [3]. The posterior form is rare representing 22.1\% of all forms in French series [4]. We report the case of a four-year-old girl admitted in our office for PHPV.

\section{Case Report}

This is a 4-year-old girl was brought by her parents for impaired visual acuity. She is the second child of 4 siblings. She has no particular history and was born a full-term pregnancy. The child had no particular history, his vaccination schedule was up to date. The mother did regular prenatal follow-up and showed no significant pathology. The father was also in good health. The child's general physical examination was normal.

There is no inbreeding between her parents.

On examination, the uncorrected visual acuity was of $6 / 60$ in both eyes. There was also a bilateral horizontal nystagmus. The ex- amination of the lens revealed a tiny opacification. The fundoscopy showed a membranous proliferation extending from the papilla to the posterior surface of the lens (Figure 1). Ocular ultrasound coupled to Doppler showed a slight microphthalmia (axial length $=19.7 \mathrm{~mm}$ in the right eye and $19.8 \mathrm{~mm}$ in the left) and an echogenic vascularized band from the papilla to the posterior surface of the lens (Figure 2). The retina was well attached. We have thus confirmed the diagnosis of PHPV. A refraction was performed; the visual acuity with optical correction was 6/36 in both eyes. No surgical option was undertaken; the patient was scheduled for a routine follow up.
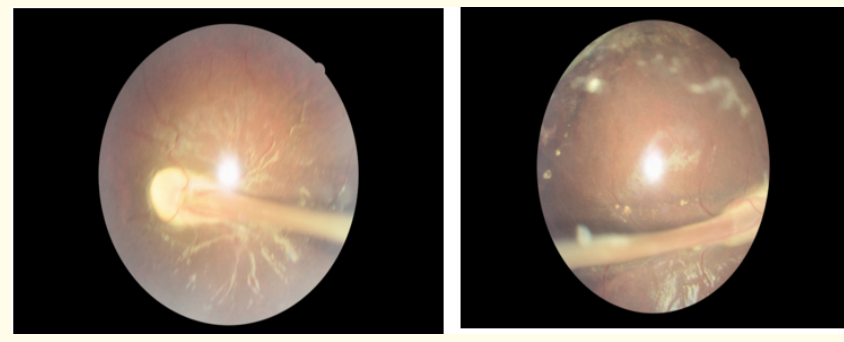

Figure 1: Photograph of the fundus showing persistence as a band from the papilla to the posterior surface of the lens. 

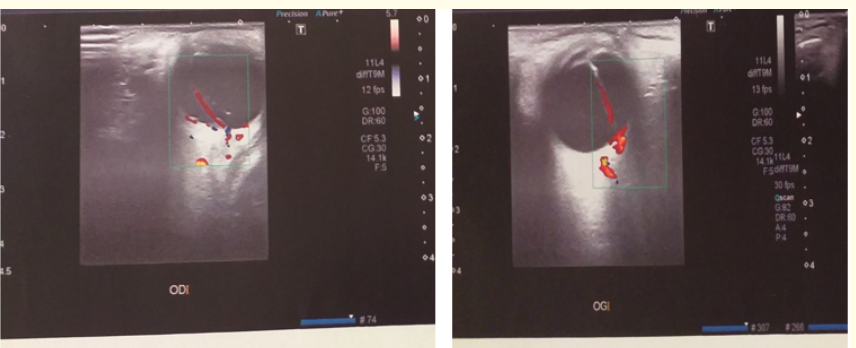

Figure 2: Doppler-coupled with ocular ultrasound showing a vascular flow band extending from the papilla to the posterior surface of the lens. $(\mathrm{OD}=$ right eye, $\mathrm{OG}=$ left eye).

\section{Discussion}

The persistent primary vitreous is a significant disorder, accounting for $4.8 \%$ of the causes of blindness and visual impairment in children in the United States [5]. During embryological development, the avascular secondary vitreous replaces the primary vascular vitreous. Hyperplasia and persistence of primary vitreous result from the failure of normal regression of the main vitreous and hyaloid vascular system with concomitant hyperplasia of embryonic connective tissue [6]. This developmental anomaly can be classified into 3 forms: anterior, posterior and mixed. The anterior form is inconstantly characterized by microphthalmia, microcornea, leukocoria due to fibrovascular membrane or cataract. The posterior form is a rare $(22.1 \%)$ whereas the anterior and the mixed forms account $35.7 \%$ and $42 \%$ respectively [4]. It may be responsible for retinal detachment by traction of the vitreous on the retina; oftentimes, it takes on a mixed appearance by the constitution of lens opacification. The mixed form is the most common. It accounted for $77 \%$ in Alexandrakis's series. This form is a direct consequence of the bipolar resorption of hyaloid tissue [3].

The bilateral forms are rare in the literature; they accounted for $2.4 \%$ in the study carried out by Pollard ZF [7].

Bilateral forms are usually associated with general anomalies [8]. In our case, it was exclusively isolated without association with any organ abnormalities.

Whatever may be the form, leukocoria seems to be the first sign of presumption. Thus, the differential diagnosis is made with the other causes of leukocoria in children. These pathologies include retinoblastoma, which is an ocular malignancy characterized by intraocular calcifications (ultrasound, CT scan), retinopathy of prematurity, where the history of prematurity is an important argu- ment for positive diagnosis. We have also the congenital cataract characterized by leukocoria which is exclusively due to lens opacification. In our clinical case, leukocoria was not the cause of admission but the blurring of vision.

Imaging is of crucial importance for the positive and differential diagnosis of hyperplasia and the persistence of primary vitreous. Ultrasound shows an echogenic band extending from the optic disc to the posterior portion of the lens. Doppler shows a vascular flow inside the band representing the persistence of the hyaloid artery [9]. CT-Scan is one of the important tools for the differential diagnosis with retinoblastoma if it is manifested by leukocoria. It provides equivalent information to ocular ultrasound [10]. MRI, requested as part of the general assessment for the posterior form, can show at the ocular level a hypersignal of the posterior segment in $\mathrm{T} 1$ and $\mathrm{T} 2$ linked to both the fibrovascular residue and the subretinal fluid [10].

These two exams are less accessible in our context, especially because of their cost. The diagnosis is commonly made early. Two cases of prenatal diagnosis have been reported by Esmer., et al [12].

In the current case, the diagnosis was late. In our country, patients do not attend health centers systematically. Also, there is no ocular exam after delivery even for babies born in health facilities.

The management of PHPV depends on the clinical form. The anterior forms are most often operated. On the other hand, in the mixed or posterior forms, the surgical indication varies according to the schools [13]. We opted for surgical abstention because the lens opacification was not total and amblyopia was already installed.

\section{Conclusion}

The persistent primary vitreous is a rare eye condition particularly the posterior and bilateral form. Ultrasound examination coupled with Doppler is very contributive for the diagnosis. Its surgical management remains controversial.

\section{Bibliography}

1. Goldberg MF., et al. "Persistent fetal vasculature (PFV): An integrated interpretation of signs and symptoms associated with persistent hyperplastic primary vitreous (PHPV). LIV Edward Jackson memorial lecture". The American Journal of Ophthalmology 124 (1997): 587-626.

2. Reese AB. "Persistent hyperplastic primary vitreous". Transactions - American Academy of Ophthalmology and Otolaryngology 59 (1955): 271-295. 
3. Alexandrakis G., et al. "Visual acuity outcomes with and without surgery in patients with persistent fetal vaculature". Ophthalmology 107 (2000): 1068-1072.

4. Roche 0., et al. "Persistance et hyperplasie du vitré primitif: étude retrospective”. Journal Français D’Ophtalmologie 30.5 (2007): 483-491.

5. Mets MB. "Childhood blindness and visual loss: an assessment at two institutions including a "new" cause". Transactions of the American Ophthalmological Society 97 (1999): 653-696.

6. Khokhar S., et al. "Approach to cataract with persistent hyperplastic primary vitreous". Journal of Cataract and Refractive Surgery 37 (2011): 1382-1385.

7. Pollard ZF. "Persistent hyperplastic primary vitreous: diagnosis, treatment and results". Transactions of the American Ophthalmological Society 95 (1997): 487-549.

8. Morton F., et al. "Persistent fetal vasculature: an integrated interpretation of signs and symptoms associated with persistant hyperplastic primary vitreous". The American Journal of Ophthalmology 124 (1997): 587-626.

9. Sanghvi D., et al. "Bilateral persistent hyperplastic primary vitreous”. Australasian Radiology 49 (2005): 72-74.

10. Bencherifa F., et al. "Intérêt de l'échographie dans la persistance et l'hyperplasie du vitré primitif. À propos de 4 cas". Journal Français D'Ophtalmologie 16 (1993): 220-224.

11. Mafee MF., et al. "Persistent hyperplastic primary vitreous (PHPV): role of computed tomography and magnetic resonance". Radiologic Clinics of North America 25 (1987): 683692.

12. Esmer AC., et al. "Prenatal Diagnosis of Persistent Hyperplastic Primary Vitreous Report of 2 Cases and Review of the Literature". Journal of Ultrasound in Medicine 35 (2016): 2285-2291.

13. Roussat B., et al. "Syndrome de persistance et d'hyperplasie du vitré primaire. Aspects cliniques et thérapeutiques". Journal Français D’Ophtalmologie 21 (1998): 501-507.

\section{Assets from publication with us}

- Prompt Acknowledgement after receiving the article

- Thorough Double blinded peer review

- Rapid Publication

- Issue of Publication Certificate

- High visibility of your Published work

Website: www.actascientific.com/

Submit Article: www.actascientific.com/submission.php Email us: editor@actascientific.com

Contact us: +919182824667 